\title{
A comparison between reported and enacted pedagogical content knowledge (PCK)
}

\section{about graphs of motion}

\author{
Ernest N. Mazibe ${ }^{1, *}$, Corene Coetzee $^{1}$ and Estelle Gaigher ${ }^{1}$ \\ ${ }^{1}$ Faculty of Education,University of Pretoria, Pretoria, South Africa \\ *Correspondence to: ernest.mazibe@up.ac.za
}

\begin{abstract}
This paper reports a case study of four grade 10 physical sciences teachers' PCK about graphs of motion. We used three data collection strategies, namely teachers' written accounts, captured by the Content Representation (CoRe) tool, interviews and classroom observations. We conceptualised the PCK displayed in the CoRe tool and the interview as "reported PCK" and the PCK demonstrated during lessons as "enacted PCK". These two manifestations of PCK were compared to establish the extent of agreement between reported and enacted PCK. We adopted the Topic Specific PCK (TSPCK) model as the framework that guided this study. This model describes TSPCK in terms of five components of teacher knowledge. Guided by the model, we designed two rubrics to assess these manifestations of TSPCK on a four point scale. The results of this study indicated that the reported PCK was not necessarily a reflection of the PCK enacted during teaching. The levels of PCK in the components were seldom higher in the enacted PCK, but tended to be similar or lower than in the reported PCK. The study implies that the enactment of PCK should be emphasized in teacher education.
\end{abstract}

Key words: Topic Specific Pedagogical Content Knowledge (TSPCK) - Content Representations (CoRes) · Graphs of motion

\section{Introduction}

Pedagogical Content Knowledge (PCK) is regarded by many scholars as an important factor that enhances teacher effectiveness (Cochran, King \& DeRuiter 1991; Eames, Williams, Hume \& Lockley 2011). The term PCK was coined by Shulman (1986) to describe the intersection between content and pedagogy (Mishra \& Koelher 2006), the knowledge about transforming content into a teachable form. Cochran and her colleagues regarded PCK as "what teaching is about" (1991, p. 5). PCK is unique to teachers (Hashweh 2005) and is not 
fixed as its application depends on different factors including context and interaction with learners (Park \& Oliver 2008). Hence different researchers have conceptualised different forms of PCK to describe its nature. These included "declarative" and "procedural" PCK (Heller, Daehler, Shinohara \& Kaskowitz 2004), "PCK in action" and "PCK on action" (Park \& Oliver 2008), and “dynamic" PCK (Alonzo \& Kim 2016). Declarative and procedural PCK refer to passive PCK, revealed in planning or when a teacher explains what s/he knows about teaching a topic. Dynamic PCK and PCK in action refer to flexible PCK that a teacher applies spontaneously in teaching events that are not necessarily anticipated, for example reactions to learners 'questions.

In the current study we conceptualised two manifestations of PCK which we described as "reported" and "enacted" PCK. The reported PCK refers to the knowledge that teachers portray in a written and spoken format, including declarative and procedural PCK. Enacted PCK refers to the knowledge that the teachers reveal during teaching, similar to dynamic PCK. Our aim was to compare these two manifestations of PCK, to establish the level of agreement between them. We selected the topic of graphs of motion because this is a fundamental topic in physics (McDermott, Rosenquist \& Van Zee 1987) and there is a paucity of information about PCK in this topic. The study was guided by the following question:

How does the teachers' reported PCK agree with their enacted PCK in the topic of graphs of motion?

\section{Graphs of motion as a curriculum topic}

Graphs of motion is an important topic in physics because it describes and represents motion (McDermott et al. 1987). In the physical sciences Curriculum and Assessment Policy Statement (CAPS) document by the Department of Basic Education (DoBE 2011) in South Africa, this topic is taught extensively at Grade 10 level focusing on motion in one dimension. According to the document (p. 56), after learners have been taught this topic, they must be able to:

- Describe the motion of an object given its position-time, velocity-time and acceleration-time graphs.

- Determine the velocity of an object from the gradient of the position-time graph.

- Know that the slope of a tangent to a position-time graph yields the instantaneous velocity at that particular time. 
- Determine the acceleration of an object from the gradient of the velocity-time graph.

- Determine the displacement of an object by finding the area under a velocity-time graph.

Research has shown that learners have difficulties regarding mechanics (Halloun \& Hestenes 1985; Lemmer 2013; McDermott et al 1987) and graphs of motion in particular (Barclay 1985; Clement 1985; Lapp \& Cyrus 2000). The most common reported difficulty in graphs of motion is that learners think that the shape of a graph resembles the path taken by the object (Barclay 1985; Clement 1985; Lapp \& Cyrus 2000).

\section{Theoretical background}

Shulman (1987) asserted that teacher knowledge should include: content knowledge, general pedagogical knowledge, PCK, curriculum knowledge, knowledge of learners and their characteristics, knowledge of educational context and knowledge of educational ends. Other scholars however conceptualised PCK as a broader knowledge, including some of the knowledge domains that Shulman (1986) regarded as being parallel to PCK (Grossman 1990; Magnusson, Krajcik \& Borko 1999; Rollnick, Bennett, Rhemtula, Dharsey \& Ndlovu 2008) and that PCK was the ultimate knowledge base for effective teaching (Cochran et al. 1991; van Driel, Verloop \& de Vos 1998). Veal and MaKinster (1999) used the different conceptualisations of PCK and developed a taxonomy to help simplify the categorisation of this construct. They divided PCK into three levels namely, general PCK, domain specific PCK and topic specific PCK. General PCK refers to PCK about teaching a specific discipline, for example science. Domain specific PCK is rooted in a particular subject within a discipline, for example physics. Topic-specific PCK is the most specific of the three levels. According to Veal and MaKinster (1999), teachers that possess a high quality of topic specific PCK are most likely well equipped in the preceding levels of PCK. Many scholars (Lowenberg-Ball, Thames \& Phelps 2008; Veal, Tippins \& Bell 1999) agree that PCK is a construct embedded in specific topics, that is, the knowledge about transforming specific content into forms that learners can understand. This view provided a starting point in the development of the Topic Specific PCK (TSPCK) model by Mavhunga and Rollnick (2013) (see Figure 1). In support of their model, Mavhunga and Rollnick (2013) mentioned that "the topic-specific nature [of PCK] suggests the need for a PCK construct that is defined more sharply to reflect the specificity of the topic rather than reference to a subject or discipline" (p. 113). We selected this model as the framework that guided the investigation of PCK about the specific topic, graphs of motion. According to Mavhunga and Rollnick (2013), TSPCK 
can be characterised by the following components: teachers' knowledge of learners' prior knowledge including misconceptions, curricular saliency, what is difficult to teach, representations including analogies and conceptual teaching strategies. The component curricular saliency refers to the knowledge a teacher has about the concepts that should be taught or left out in a topic, the importance of the concepts, the sequence in which the concepts should be presented and the interconnections amongst the concepts. We evaluated teachers' level of competence in each of these components for their reported as well as enacted PCK so that they could be compared.

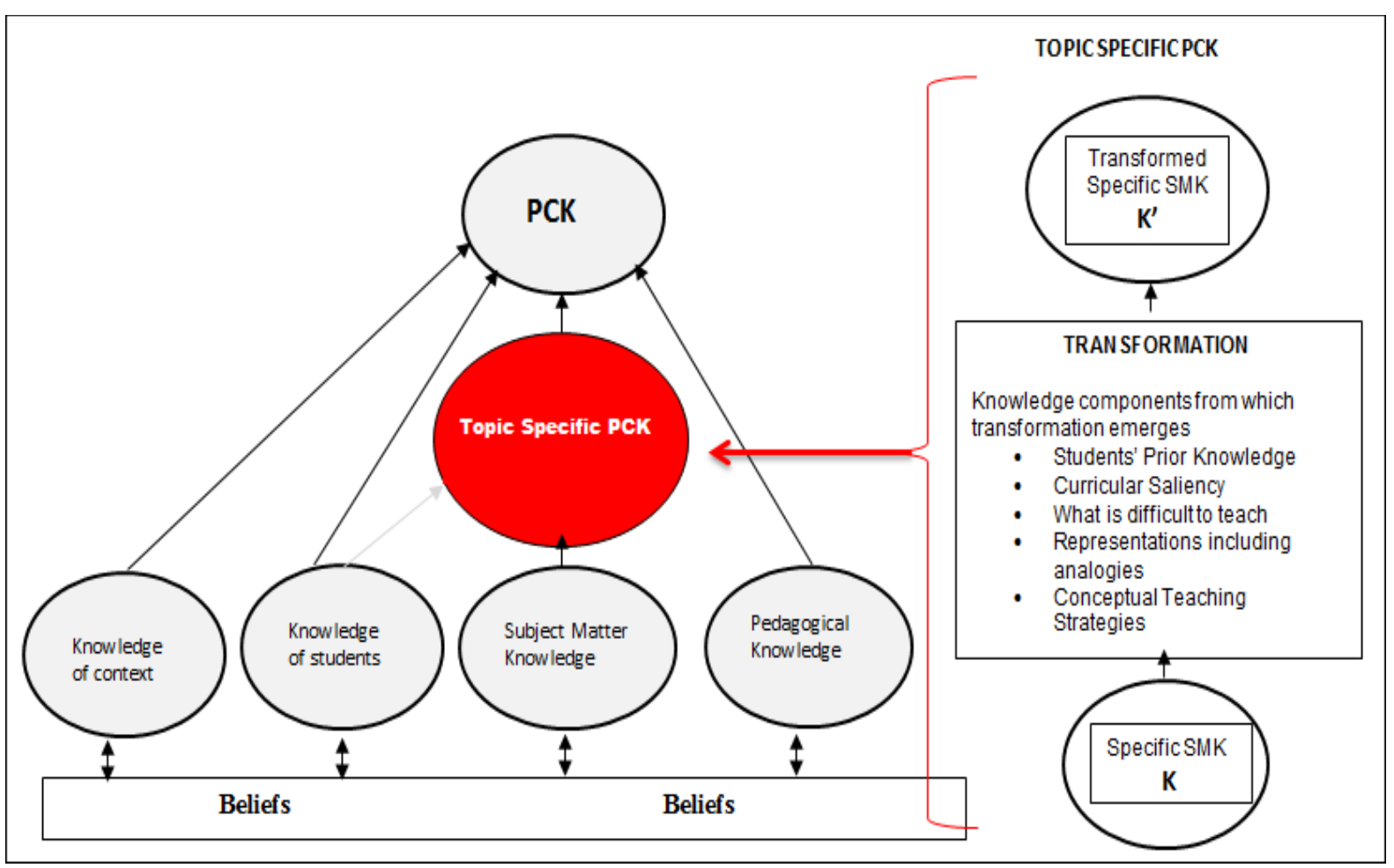

Fig.1 The TSPCK model (Mavhunga \& Rollnick, 2013).

PCK is an elusive construct in science education because it cannot be observed directly (Kagan, 1990), and is described as being personal and private (Hashweh 2005). Therefore it is difficult to explore PCK considering that teachers also find it challenging to articulate it (Baxter \& Lederman 1999; Loughran, Mulhal \& Berry 2004). However, researchers used different strategies in their studies to access teachers' PCK. These included lesson plans (Van Der Valk \& Broekman 1999), topic specific PCK tests (Juttner \& Neuhaus 2012; Mavhunga \& Rollnick 2013), interviews (Juttner \& Neuhaus 2012) and lesson observations (Rollnick et al. 2008). Loughran et al. (2004) designed a useful instrument, known as Content Representation (CoRe) tool to access teachers' PCK about specific topics written in a tabular format (see Table 1). Many scholars have used this instrument to capture teachers' PCK in 
different topics including amount of substance (Padilla, Ponce-de-Leon, Rembrado \& Garritz 2008), global warming (Chordnork \& Yuenyong 2014), nature of organisms (Chapoo, Thatong \& Halim 2014) and Ohm's law (Chantanarima \& Yuenyong 2014). This tool firstly requires teachers to select "big ideas" which they regard as the major concepts within a particular content area (Bertram \& Loughran 2012; Padilla et al. 2008). The instrument further prompts teachers to reason about the chosen big ideas, which requires them to write down their unique views and approaches towards teaching those ideas. The quality of teachers' PCK is not necessarily determined by the amount of information written in the CoRe, but by the quality of the information as well as how it is put into action during teaching (Abell 2008).

Table 1 The CoRe template (Loughran, Mulhall \& Berry 2004)

\begin{tabular}{|l|l|l|l|}
\hline Content Area:............... & Big idea A & Big idea B & Big idea C \\
\hline What do you intend the learners to learn about this idea? & & & \\
\hline Why is it important for learners to know this? & & & \\
\hline $\begin{array}{l}\text { What else do you know about this idea (that you do not intend } \\
\text { learners to know yet)? }\end{array}$ & & & \\
\hline $\begin{array}{l}\text { What are the difficulties/limitations connected with teaching this } \\
\text { idea? }\end{array}$ & & & \\
\hline $\begin{array}{l}\text { What is your knowledge about learners' thinking that influences your } \\
\text { teaching of these ideas? }\end{array}$ & & \\
\hline $\begin{array}{l}\text { Are there any other factors that influence your teaching of these } \\
\text { ideas? }\end{array}$ & & & \\
\hline $\begin{array}{l}\text { What are your teaching procedures (and particular reasons for using } \\
\text { these to engage with this idea)? }\end{array}$ & & & \\
\hline $\begin{array}{l}\text { Specific ways of ascertaining learners' understanding or confusion } \\
\text { around this idea (include a likely range of responses). }\end{array}$ & & \\
\hline
\end{tabular}

PCK portrayed in a written format has received criticism. According to Kagan (1990), this PCK may be neat, yet artificial and irrelevant to real classroom encounters. On the other hand, this PCK is important to teaching because it informs lesson preparation (Alonzo \& Kim 2016; Chantanarima \& Yuenyong 2014).

\section{Methodology}

PCK had been predominantly investigated through qualitative means (Baxter \& Lederman 1999, Aydin \& Boz 2012), hence we also conducted a qualitative research methodology using a case study research design (Hancock 2002). We purposively and conveniently 
selected four Grade 10 physical sciences teachers as participants. The participants and their learners were not first language English speakers. Their biographical information is summarised in Table 2.

Table 2 Teachers' biographical information

\begin{tabular}{|c|c|c|c|}
\hline Teachers' identification & Highest qualification & $\begin{array}{l}\text { Teaching experience } \\
\text { (years) }\end{array}$ & Type of school \\
\hline Ms VM & $\begin{array}{l}\text { B.Ed Degree in Science } \\
\text { Education }\end{array}$ & Six & Adequately resourced \\
\hline Ms SC & $\begin{array}{l}\text { Post Graduate Certificate } \\
\text { in Science Education } \\
(\mathrm{PGCE})\end{array}$ & Three & Adequately resourced \\
\hline $\mathrm{Ms} \mathrm{MH}$ & $\begin{array}{l}\text { Higher Diploma in } \\
\text { Science Education }\end{array}$ & Five & Poorly resourced \\
\hline $\mathrm{Mr} \mathrm{KZ}$ & $\begin{array}{l}\text { B.Ed Degree in Science } \\
\text { Education }\end{array}$ & Three & Adequately resourced \\
\hline
\end{tabular}

We explored the PCK of the teachers without intervening in any way, using the CoRe tool, interviews and classroom observations. The CoRe tool contained two sections, $\mathrm{A}$ and $\mathrm{B}$, in the same document. Section A instructed the teachers to list all concepts that they regarded as the key ideas of this topic. The first author explained to the teachers what key ideas are and presented examples of key ideas of other topics to enhance their understanding. Section B instructed the teachers to respond to the questions/prompts in Table 1 based on their chosen key ideas. Despite the explanations of how to complete the CoRe tool, the teachers still had difficulties in portraying their PCK using this instrument. Of course, as with most instruments, it is always possible that not all relevant information is supplied by the participant; this is a limitation in all qualitative research. CoRe prompts were also used as interview questions to supplement the PCK that the teachers portrayed in the CoRe tool (Chantanarima \& Yuenyong 2014; Padilla et al. 2008). In the analysis, we combined data from the CoRe tool and interviews, labelling it "reported PCK". We then observed the teachers teaching the topic to gather data reflecting their enacted PCK. We also designed an expert CoRe that served as canonical PCK, which refers to the knowledge that belongs to the teaching profession, generated through research and/or collective insights of experts (Smith \& Banilower 2015). This knowledge also serves as the standard for the assessment of PCK (Smith \& Banilower, 2015), hence the CoRes of the teachers were assessed against the expert CoRe. We regarded the expert CoRe as an exemplary display of PCK, although it is not the only way in which graphs of motion concepts can be adequately organised in the CoRe tool. 
Table 3 only shows the key ideas from the expert CoRe, the complete CoRe can be accessed from Mazibe (2017).

Table 3 Section A of the expert CoRe

\begin{tabular}{|l|l|}
\hline Key idea & Sub-ordinate idea \\
\hline $\begin{array}{l}\text { Understand these graphs: } \\
\text { - Position-time graph }\end{array}$ & $\begin{array}{r}\text { Understand the graphs under these conditions: } \\
\text { Velocity-time graph }\end{array}$ \\
& $\begin{array}{l}\text { Stationery object in the origin, positive } \\
\text { and negative direction }\end{array}$ \\
& $\begin{array}{l}\text { Constant velocity in the positive and } \\
\text { negative direction. } \\
\text { - Acceleration-time graph }\end{array}$ \\
\hline $\begin{array}{l}\text { Gradient of a position-time graph (including acceleration in the positive or } \\
\text { tangents and secants) }\end{array}$ & $\begin{array}{l}\text { Represents velocity (instantaneous velocity and } \\
\text { average velocity) }\end{array}$ \\
\hline Gradient of a velocity-time graph & Represents acceleration. \\
\hline Area under a velocity-time graph & Represents displacement, a change in position. \\
\hline
\end{tabular}

The teachers were then observed teaching graphs of motion to gather data reflecting their enacted PCK. Regarding the classroom visits, the teachers were requested to teach the whole topic in our presence like they would normally do. According to the CAPS document (p. 56), teachers needed six hours to complete the topics of graphs and equations of motion (DoBE 2011). We believe that at least four of the six hours were necessary for graphs of motion only. However, all the teachers finished within two periods, about an hour each.

To analyse the data, we designed two TSPCK rubrics, one for the reported PCK (Table 4) and the other for the enacted PCK (Table 5), based on the five TSPCK components from the theoretical framework. Mavhunga and Rollnick's (2013) rubric, that was designed to assess teachers' PCK about chemical equilibrium in a TSPCK test, was adapted to suit CoRes and interviews about graphs of motion. Regarding enacted PCK, we designed a rubric as none was available in the literature at that stage. The rubrics were used to assign the revealed competences in four categories; limited, basic, developing and exemplary (Mavhunga \& Rollnick 2013; Park, Jang, Chan \& Jung 2011). The second and third author, experts in 
Table 4 Rubric for assessing TSPCK about graphs of motion as reported in CoRe tool and interviews

\begin{tabular}{|c|c|c|c|c|}
\hline TSPCK Component & Limited & Basic & Developing & Exemplary \\
\hline Learners' prior knowledge & $\begin{array}{l}\text { No identification/ } \\
\text { acknowledgement of learners' } \\
\text { prior knowledge or } \\
\text { misconceptions. }\end{array}$ & $\begin{array}{l}\text { Identified one major misconception } \\
\text { and other minor misconceptions. } \\
\text { Identifies basic learner errors related } \\
\text { to mathematical concepts without } \\
\text { linking it to science concepts. }\end{array}$ & $\begin{array}{l}\text { Identified two major } \\
\text { misconceptions and other minor } \\
\text { misconceptions. }\end{array}$ & $\begin{array}{l}\text { Identified three or more major } \\
\text { misconceptions and other minor } \\
\text { misconceptions. }\end{array}$ \\
\hline Curricular saliency & $\begin{array}{l}\text { Identified irrelevant key ideas/ } \\
\text { pre-concepts as key ideas. } \\
\text { Illogical sequencing of concepts } \\
\text { due to inadequate key ideas. } \\
\text { No indication of the } \\
\text { interrelatedness between } \\
\text { concepts due to inadequate key } \\
\text { ideas. } \\
\text { Reasons for the importance of } \\
\text { concepts are absent. }\end{array}$ & $\begin{array}{l}\text { Identified two relevant key ideas } \\
\text { without sub-ordinate ideas. } \\
\text { Pre-concepts are mixed with big } \\
\text { ideas. } \\
\text { Sequencing has an illogical placing of } \\
\text { at least one key idea. } \\
\text { Indication of the interrelatedness } \\
\text { between concepts is clumsy due to the } \\
\text { illogical placing of a key idea. } \\
\text { The importance of concepts exclude } \\
\text { scaffolding into subsequent topics. }\end{array}$ & $\begin{array}{l}\text { Identified three relevant key ideas. } \\
\text { Identified supporting sub-ordinate } \\
\text { ideas. } \\
\text { Key ideas are sequenced logically. } \\
\text { The indication of the } \\
\text { interrelatedness between concepts } \\
\text { is evident. } \\
\text { Reasons for the importance of } \\
\text { concepts includes scaffolding, but } \\
\text { the subsequent topics are not } \\
\text { specified. }\end{array}$ & $\begin{array}{l}\text { Identified four or more big ideas. } \\
\text { Identified sub-ordinate ideas and } \\
\text { showed links with key ideas. } \\
\text { Concepts are sequenced logically. } \\
\text { The indication of the } \\
\text { interrelatedness amongst concepts } \\
\text { is adequate. } \\
\text { Reasons for the important of } \\
\text { concepts includes scaffolding and } \\
\text { the subsequent topics are specified. }\end{array}$ \\
\hline What is difficult to teach? & $\begin{array}{l}\text { No indication of concepts/ideas } \\
\text { that are difficult to teach. } \\
\text { Reasons for the difficulty or } \\
\text { gate-keeping concepts are not } \\
\text { specified. }\end{array}$ & $\begin{array}{l}\text { Identified broad concepts as difficult. } \\
\text { Reasons for the difficulties are not } \\
\text { specific to the key ideas. e.g. "their } \\
\text { mathematics knowledge is poor". }\end{array}$ & $\begin{array}{l}\text { Identified specific concepts as } \\
\text { difficult. } \\
\text { Outlined reasons related to } \\
\text { learners' common difficulties. }\end{array}$ & $\begin{array}{l}\text { Identified specific concepts as } \\
\text { difficult. } \\
\text { Outlined gate keeping concepts as } \\
\text { well as learners' misconceptions } \\
\text { perpetuating the difficulties. }\end{array}$ \\
\hline $\begin{array}{l}\text { Representations including } \\
\text { analogies }\end{array}$ & Representations not identified. & $\begin{array}{l}\text { Identified a relevant representation. } \\
\text { No information about how the } \\
\text { representation works and which } \\
\text { concepts it supports. }\end{array}$ & $\begin{array}{l}\text { Identified a relevant representation. } \\
\text { Outlined how the representation } \\
\text { supports the explanations of } \\
\text { concepts. }\end{array}$ & $\begin{array}{l}\text { Identified a variety of relevant } \\
\text { representations and how the } \\
\text { representations support the } \\
\text { confrontation of misconceptions } \\
\text { and difficult concepts. }\end{array}$ \\
\hline Conceptual teaching strategies & $\begin{array}{l}\text { No strategy to expose learners' } \\
\text { difficulties and misconceptions. } \\
\text { No strategy to confront and } \\
\text { address misconceptions and } \\
\text { difficulties. } \\
\text { No indication of how key ideas } \\
\text { will be explained. } \\
\text { No intentions to involve } \\
\text { representations to engage with } \\
\text { learners. } \\
\text { Overall highly teacher centred } \\
\text { lesson. }\end{array}$ & $\begin{array}{l}\text { Evidence of activities to expose } \\
\text { learners' misconceptions and } \\
\text { difficulties. } \\
\text { Verbal confrontation of } \\
\text { misconceptions and difficulties. } \\
\text { Indication of how some key ideas will } \\
\text { be explained: no explanation of the } \\
\text { interrelatedness. } \\
\text { Representations are outlined but } \\
\text { concepts to be supported are absent. } \\
\text { Limited involvement of learners. }\end{array}$ & $\begin{array}{l}\text { Evidence of activities to expose } \\
\text { learners' misconceptions and } \\
\text { difficulties. } \\
\text { Confrontations of difficulties and } \\
\text { misconceptions evident. } \\
\text { Indication of how some key ideas } \\
\text { will be explained and interrelated. } \\
\text { Representations identified to } \\
\text { explain concepts in general. } \\
\text { There is evidence of learner } \\
\text { involvement. }\end{array}$ & $\begin{array}{l}\text { Evidence of activities to expose } \\
\text { learners' misconceptions and } \\
\text { difficulties. } \\
\text { Confrontation addresses gate- } \\
\text { keeping concepts (misconceptions) } \\
\text { beforehand. } \\
\text { Indication of how all key ideas will } \\
\text { be explained and interrelated. } \\
\text { Representations to be used to } \\
\text { explain concepts in general and the } \\
\text { ones identified as difficult. } \\
\text { Highly learner centred lesson. }\end{array}$ \\
\hline
\end{tabular}


Table 5 Rubric for assessing TSPCK about graphs of motion enacted during teaching

\begin{tabular}{|c|c|c|c|c|}
\hline TSPCK Component & Limited & Basic & Developing & Exemplary \\
\hline Learner' prior knowledge & $\begin{array}{l}\text { No facilitation of discussions that } \\
\text { expose learner' misconceptions. } \\
\text { Learners are spoon-fed with the } \\
\text { necessary prior knowledge. }\end{array}$ & $\begin{array}{l}\text { Facilitates discussions that expose } \\
\text { learners' misconceptions. } \\
\text { Confronts some of them by } \\
\text { providing standardised definitions. }\end{array}$ & $\begin{array}{l}\text { Facilitates discussions that expose } \\
\text { learners' misconceptions. } \\
\text { Confronts most of them by } \\
\text { expanding and rephrasing further. }\end{array}$ & $\begin{array}{l}\text { Exposed learners' misconceptions } \\
\text { through discussions } \\
\text { Confronts all of them by expanding } \\
\text { and rephrasing further. } \\
\text { Confirms learners' understanding. }\end{array}$ \\
\hline Curricular saliency & $\begin{array}{l}\text { Explains irrelevant concepts. } \\
\text { Leaves out important concepts in } \\
\text { the topic. } \\
\text { Sequencing of all key ideas is } \\
\text { illogical. } \\
\text { The interconnections between } \\
\text { concepts are not explained. }\end{array}$ & $\begin{array}{l}\text { Relevant key ideas are discussed } \\
\text { but not given attention equally. } \\
\text { Sequencing has illogical placing of } \\
\text { most of the key ideas. } \\
\text { Explains the interconnection } \\
\text { between some concepts. }\end{array}$ & $\begin{array}{l}\text { Relevant concepts are explained } \\
\text { and given enough attention. } \\
\text { Most of the key ideas are } \\
\text { sequenced logically. } \\
\text { The interconnection between most } \\
\text { concepts is also logical. }\end{array}$ & $\begin{array}{l}\text { Explains concepts giving them the } \\
\text { attention they deserve. } \\
\text { All concepts are sequenced } \\
\text { logically, in the order of } \\
\text { importance. } \\
\text { Also explains the interconnections } \\
\text { between all concepts. }\end{array}$ \\
\hline What is difficult to teach? & $\begin{array}{l}\text { No facilitation of discussions that } \\
\text { expose difficulties } \\
\text { Identified difficult concepts are not } \\
\text { confronted/confronted incorrectly }\end{array}$ & $\begin{array}{l}\text { Facilitation of discussions that } \\
\text { reveal difficulties. } \\
\text { No expansion of explanations of } \\
\text { the difficult concepts. }\end{array}$ & $\begin{array}{l}\text { Facilitation of discussions that } \\
\text { reveal difficulties. } \\
\text { Teacher expands on the } \\
\text { explanation of difficult concepts. }\end{array}$ & $\begin{array}{l}\text { Facilitation of discussions that } \\
\text { reveal difficulties. } \\
\text { Confrontation starts from gate- } \\
\text { keeping concepts and concepts are } \\
\text { expanded. } \\
\text { Teacher confirms learners' } \\
\text { understanding }\end{array}$ \\
\hline $\begin{array}{l}\text { Representations including } \\
\text { analogies }\end{array}$ & $\begin{array}{l}\text { Representations not used in the } \\
\text { lesson. }\end{array}$ & $\begin{array}{l}\text { Representations are seldom used. } \\
\text { Representations have potential to } \\
\text { induce misconceptions. }\end{array}$ & $\begin{array}{l}\text { Representations are used to explain } \\
\text { concepts and confront learners' } \\
\text { difficulties. }\end{array}$ & $\begin{array}{l}\text { Representations used to confront } \\
\text { and expand explanations of } \\
\text { difficult concepts. } \\
\text { Representations used to confirm } \\
\text { learners' understanding. }\end{array}$ \\
\hline Conceptual teaching strategies & $\begin{array}{l}\text { Explains new concepts without } \\
\text { exploring and developing prior } \\
\text { knowledge } \\
\text { Concepts are sequenced illogically, } \\
\text { and interconnections are not } \\
\text { explained. } \\
\text { Teacher doesn't use } \\
\text { representations to engage with } \\
\text { concepts. } \\
\text { Lesson is highly teacher centred. }\end{array}$ & $\begin{array}{l}\text { Teachers asks closed ended } \\
\text { questions. } \\
\text { Confronts misconceptions but } \\
\text { doesn't expand explanations. } \\
\text { Key ideas are explained in } \\
\text { isolation as well as their } \\
\text { interrelatedness. } \\
\text { Representations seldom used or } \\
\text { used ineffectively to engage with } \\
\text { concepts. } \\
\text { Limited involvement of learners. }\end{array}$ & $\begin{array}{l}\text { Teacher ask few higher order } \\
\text { questions } \\
\text { Expands confrontation of } \\
\text { misconceptions but doesn't } \\
\text { confirm understanding. } \\
\text { Most key ideas are almost } \\
\text { sequenced logically with links. } \\
\text { Representations used to engage } \\
\text { with concepts, but only the teacher } \\
\text { uses them. } \\
\text { Evidence of encouraged learner } \\
\text { involvement. }\end{array}$ & $\begin{array}{l}\text { Teacher asks higher order } \\
\text { questions. } \\
\text { Expands confrontation of } \\
\text { misconceptions and confirms } \\
\text { understanding. } \\
\text { All key ideas are sequenced } \\
\text { logically as well as the links } \\
\text { between them consecutive } \\
\text { concepts. } \\
\text { Representations used by learners as } \\
\text { well to confirm understanding. } \\
\text { Generally, learner centred lesson. }\end{array}$ \\
\hline
\end{tabular}


science education, reviewed the rubrics for content validity to give a true reflection of TSPCK aspects (Maree 2010). The first author then piloted the rubrics with two colleagues to establish whether the descriptions of the categories adequately distinguish between the different levels of competence. The credibility of the interpretation of the PCK, as well as the scores assigned to the teachers' competences were also continuously reviewed by the second and third author (Maree 2010).

\section{Findings}

\section{Case study 1 - Ms VM}

Table 6 summarises the levels at which we scored Ms VM's competences across the TSPCK components for both the reported and enacted PCK.

Table 6 A summary of Ms VM's competences in her reported and enacted PCK.

\begin{tabular}{|l|c|c|c|c|}
\hline TSPCK Component & Limited & Basic & Developing & Exemplary \\
\hline Learners' prior knowledge. & & E & R & \\
\hline Curricular saliency. & R & E & & \\
\hline What is difficult to teach? & & RE & & \\
\hline Representations including analogies. & & E & R & \\
\hline Conceptual teaching strategies. & & RE & & \\
\hline
\end{tabular}

Key: R - Reported PCK, E - Enacted PCK

Ms VM chose the following key ideas in her CoRe: (i) why do we use graphs in science, (ii) motion with constant velocity and (iii) motion with constant acceleration.

\section{Learners' prior knowledge}

Ms VM revealed awareness of learners' misconceptions in graphs of motion in her reported PCK. She mentioned that learners confuse the direction of velocity and acceleration, and that they also confuse the direction of an object's position vector with that of its velocity (McDermott et al. 1987). However, she also regarded "negative time" as a misconception, whereas this is the time elapsed before the motion was studied. Considering the fact that she identified two major misconceptions reported in literature, we rated her competence as 'developing'. During teaching, Ms VM indeed told learners that graphs of motion can never be constructed on the negative horizontal axis (containing negative time values) because time is not reversible. . Although she explored prior knowledge of velocity and acceleration, she did not refer to direction to address the confusion that she mentioned in her reported PCK. Her focus was on the direction of the two. We observed that learners indeed revealed a 
misconception related to the confusion of the direction of velocity and position. They thought that the magnitude of the displacement of an object moving in the negative direction is necessarily decreasing. Ms VM addressed this confusion while she walking in the negative direction from the origin to show them that her displacement was in fact increasing in that instance. We rated her revealed competence as 'basic' considering that she did not pay attention to the "velocity-acceleration" misconception.

\section{Curricular saliency}

During the interview, Ms VM added the following key ideas to the ones selected in her CoRe: learners must be able to identify and draw position-time, velocity-time and acceleration-time graphs, determine the following variables; displacement, velocity, speed and acceleration, and interpret the graphs. However, she also wrote explicitly that learners did not have to learn about two key ideas of this topic, gradient and area (See Table 3), when responding to the third prompt of the CoRe tool. The variables that she listed as key ideas during the interview are also determined through gradient and area in this topic. This suggested that her knowledge of important concepts, the order of teaching them and the interrelatedness between them was inadequate. As a result we scored her competence as 'limited'. During the lesson, Ms VM did not teach the concept of area under a velocity-time graph, similar to the exclusion of this concept in her CoRe. On the contrary, Ms VM briefly discussed gradient, thus sequencing her teaching of concepts adequately although she poorly explained the interrelatedness between the concepts. For example, regarding a position-time graph and velocity, Ms VM said "if we do the gradient or the slope (of a position-time graph), you gonna [going to] say it is still delta $\mathrm{x}$ over delta $\mathrm{t}$, which is the velocity" without showing learners how this is the case. The key idea "motion with constant acceleration" that she chose was not developed in the lesson. Hence we scored her competence as 'basic', one level higher than her reported PCK had suggested.

\section{What is difficult to teach?}

In the interview, Ms VM mentioned that learners find it difficult to understand how graphs of motion are related; hence they regard all of them as position-time graphs and subsequently interpret them incorrectly. However, as mentioned before, she explicitly indicated in her CoRe that gradient and area need not be taught. This indicates that she did not appreciate the importance of these concepts to explain the interrelatedness of the graphs. As a result, we regarded her competence as 'basic' in her reported PCK. In contrast, during the lesson Ms 
VM used gradient to explain the link between a position-time and a velocity-time graph, although her explanation was inadequate as shown in the paragraph above. She also explained the interpretations of a position-time graph, while "walking-the-graph" without referring to velocity changes. Later in the lesson she constructed a separate velocity-time graph and interpreted it without relating it to either a position-time or an acceleration-time graph. Although she was aware that learners do not understand the relationships between graphs, she did not use such opportunities to explain them. Consequently, we also regarded Ms VM's enacted knowledge about concepts that are difficult to teach as 'basic'.

\section{Representations including analogies}

In her reported PCK, Ms VM indicated "walking-the-graph" as a strategy that helped her address learners' misconceptions and helped them visualise motion. To address the confusion about the direction of position and velocity, Ms VM said “...what I try and do is show by walking that this is my point of origin, so even though I'm in the east side, I turn around and move direction west". She revealed knowledge about a representation that addresses a major misconception effectively, which led to her reported competence being scored 'developing'. During teaching we observed that she used the same representation to address learners' confusions when they thought that the magnitude of the displacement of an object moving in the negative direction is necessarily decreasing. However, she only used this representation once during teaching. For example, she interpreted a velocity-time graph showing changes in velocity and direction without "walking-the-graph". We believe that using the representation could have enhanced learners' understanding, as they kept telling her that they do not understand. She also used diagrams from a textbook showing a human figure to represent motion in different sections below the graphs (Figure 2).

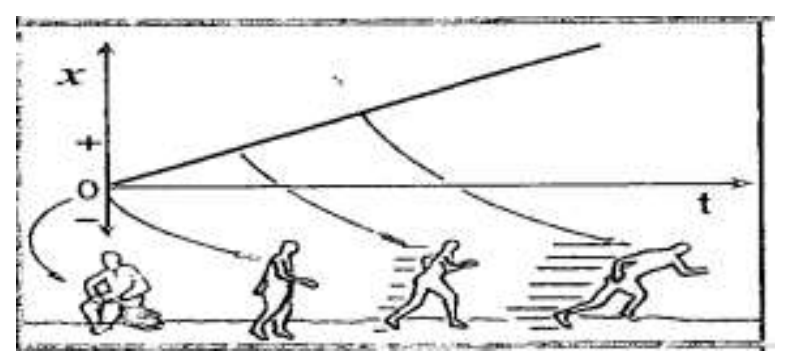

Fig. 2 Position-time graph used by Ms VM

However, the diagrams were poorly selected as some of the information was presented incorrectly. For example in Figure 2, the person appears to be running faster and faster whereas the linear position-time graph actually depicts motion at constant velocity. Clearly 
Ms VM did not pick this up. Thus we scored her use of representations as 'basic' for her enacted PCK, one level lower than the score allocated for her reported PCK.

\section{Conceptual teaching strategies}

Ms VM's reported PCK indicated mostly direct teaching and "walking-the-graph" as teaching strategies. For example, she suggested direct teaching as a strategy to address the concept of negative time as she believed it was a misconception. She said "learners must be told that time will always be measured on the positive $\mathrm{x}$-axis [horizontal axis] and be reminded about vectors and scalars". As discussed previously under the component "what is difficult to teach', Ms VM indicated that learners find it difficult to understand the relationship between graphs. Yet she did not indicate the possibility to use the geometric concepts of gradient and area as a strategy to clarify the relationship between graphs. In fact she explicitly indicated that learners do not need to learn about gradient and area. This oversight reflects poorly on her conceptual teaching strategies. Nevertheless, she reported a representation "walking-the-graph" as a strategy that addresses learners' misconceptions about the direction of position and velocity. As a result, we regarded her reported knowledge about conceptual teaching strategies as 'basic'.

During the lesson, Ms VM indeed used the representation "walking-the-graph" to address a misconception about negative displacement. We also observed that she asked questions as a strategy to engage with learners. However, she directed them into answering correctly. For example, she asked "if an object is moving with a constant velocity, is it accelerating?" and immediately said "no, because acceleration is the change in..." which led learners into saying "velocity". She constructed two position-time graphs with different gradients on the same set of axes and asked learners to comment on the velocities. When learners answered incorrectly, Ms VM corrected them using direct instruction when she said "the greater the gradient, the higher the velocity". She also poorly explained the interrelatedness between a curved position-time graph and a velocity-time graph:

"With such a graph, the gradient of the tangent to this graph shows instantaneous velocity, using a triangle is not going to work because the graph is curved can you see? But you can choose a point and then draw a triangle that includes the point and then calculate the gradient of the line cutting through the point".

We noticed that she did not ensure that learners understood what a tangent is, and that she did not construct it on the graphs to support her explanation. Apart from walking the graph to 
model directions of position and displacement, she did not utilise any other conceptual strategies, consequently we scored her enacted competence as 'basic'.

\section{Case study 2 - Ms SC}

Table 7 summarises the levels at which we scored Ms SC's competences across the TSPCK components for both the reported and enacted PCK.

Table 7 A summary of Ms SC's competences in her reported and enacted PCK.

\begin{tabular}{|l|c|c|c|c|}
\hline TSPCK Component & Limited & Basic & Developing & Exemplary \\
\hline Learners' prior knowledge. & & $\mathbf{R E}$ & & \\
\hline Curricular saliency. & & & $\mathbf{R E}$ & \\
\hline What is difficult to teach? & & $\mathbf{E}$ & $\mathbf{R}$ & \\
\hline Representations including analogies. & & $\mathbf{R E}$ & & \\
\hline Conceptual teaching strategies. & & $\mathbf{R E}$ & & \\
\hline
\end{tabular}

Key: R - Reported PCK, E - Enacted PCK

The information about teaching graphs of motion that could be elicited from Ms SC's CoRe was scant and inadequate, since she focused on general teaching rather than the topic at hand. Hence we predominantly describe the PCK that she reported during the interview. Nevertheless, she chose the following key ideas in her CoRe: (i) explain graphs like a mathematics teacher, (ii) link $x$ and y to science concepts - velocity, displacement and time, (iii) give a summary, and (iv) practice, practice, practice! Only the second key idea was specific to graphs of motion.

\section{Learners' prior knowledge}

Ms SC indicated two difficulties in learners' prior knowledge of mathematics only. She said learners do not know the difference between the horizontal and vertical axes and reading values on the axes, a difficulty not reported in literature and one that we believe could easily be corrected. She also mentioned that learners don't understand that the gradient of a straight line graph stays constant whereas that of a curved graph varies. In literature, scholars have reported that it is the gradient of a curved graph that is problematic for learners (Frauenknecth \& Jordan 2005). With regard to this major challenge, we scored Ms VM's reported knowledge as 'basic'. During the lesson Ms SC also dwelled much on learners' prior knowledge of mathematics. However, she did not explore learners' understanding of gradient and area through questioning but chose to tell them what these concepts are. When she asked what the gradient of a diagonal straight line was in order to explore their prior knowledge, 
they answered "one" instead of "constant". Upon realising that they are mistaken, she used direct instruction to correct them when she said "the gradient of a straight line is not always one, but it is rather constant". It was evident that Ms SC's knowledge of learners' thinking was restricted, hence we scored her competence as 'basic'.

\section{Curricular saliency}

During the interview Ms SC added the following key ideas: position-time, velocity-time and acceleration-time graphs, as well as the concept of gradient and area. She also mentioned that "in maths you say gradient equals $\mathrm{y}_{2}-\mathrm{y}_{1}$ over $\mathrm{x}_{2}-\mathrm{x}_{1}$, then if you substitute that (motion variables) into your formula for gradient, they (learners) can easily recognise the formulas that we used before we started graphs of motion". The formulae she referred to are the definitions of velocity and acceleration. This indicated that she sequenced and developed learners' understanding of the interrelatedness of graphs of motion through the concept of gradient. Hence we regarded her reported knowledge as 'developing'.

During the lesson she sequenced concepts and discussed the interrelatedness of all graphs of motion through the concept of gradient and area, adequately for graphs of constant motion. She substituted motion variables in the formulae for gradient and requested learners to identify the symbolic definitions of velocity and acceleration. She also calculated the gradients, as well as the area under a velocity-time graph, and used the magnitudes to construct the corresponding graphs. However, her discussion of accelerated motion was less adequate and is described in the next TSPCK component. Based on the fact that she gave a comprehensive discussion of the graphs of constant motion through gradient and area, we regarded her enacted competence as 'developing'.

\section{What is difficult to teach?}

During the interview, Ms SC elaborated on learners' difficulties regarding the concept of gradient. She indicated a difficulty reported in literature that learners find it difficult to calculate, interpret and relate gradients of graphs (of motion) to physical phenomena, evident in their omission of units in their calculations (Woolnough 2000). She also mentioned that learners find it difficult to calculate the area under a velocity-time graph if there are complex shapes such as a trapezium instead of a square, rectangle and triangle. We believed that these two difficulties were gate-keeping concepts for the third difficulty that she identified, that is, learners find it difficult to understand the interrelatedness between graphs of motion. 
Inferring from the identified difficulties, we regarded $\mathrm{Ms} \mathrm{SC}$ 's reported competence as 'developing'.

During the lesson, Ms SC supported learners when calculating gradients of graphs of motion and recognising the represented motion variables. She also explained the interrelatedness between graphs of motion at constant velocity through gradient and area as shown in the previous TSPCK component. Regarding accelerated motion, Ms SC merely mentioned that the gradient of a curved position-time graph changes, without referring to the concepts of change in velocity or acceleration. She did not draw a tangent on different points on the position-time graph, and calculate its gradient to show learners that the gradient keeps changing. Thus she explained the interrelatedness poorly. Consequently, we regarded her enacted competence as 'basic', one level lower than her reported PCK suggested.

\section{Representations including analogies}

Ms SC regarded a ticker timer experiment as a representation that helps learners conceptualise graphs of motion. However, she did not describe how she implements it and the concepts that she explains using it. She also said "at this stage I haven't figured out a visual representation on how to show a pattern [sequencing of concepts] and how the pattern works", suggesting that she considered ticker timer experiments as insufficient. Hence we regarded her competence as 'basic'. During the lesson, Ms SC did not use a ticker timer experiment. However, she used another representation, "walking-the-graph", to explain direction after a calculation in which the gradient of a decreasing position-time graph came out negative. However, since she explained an elementary concept through this representation and only once, we regarded her enacted competence as 'basic'.

\section{Conceptual teaching strategies}

Ms SC advocated that the best way to teach this topic is to firstly explain applicable mathematics concepts. This possibly helped her address learners' difficulties regarding the concept of gradient. She also said:

“there are two things that I teach them, that's basically writing ' $p$ ' [position], then underneath it a ' $v$ ' [velocity] and underneath it an ' $a$ ' [acceleration] and show them that if you go one direction (for example obtaining velocity from the position-time graph) you use the gradient and if you go the other [opposite] direction you use the area”. 
However, apart from showing learners when to calculate gradient and area, she did not report how she will show them how to calculate the variables. She also mentioned ticker timer experiments as a strategy that supports the explanation of concepts in the topic as indicated under representations. However, she did not have a conceptual strategy to use this representation effectively. Therefore we regarded her reported knowledge of teaching strategies as 'basic'.

During the lesson, she indeed started from applicable mathematical concepts in the topic. However, she did not explore learners understanding of the concepts but rather presented them using direct instruction. Not only did Ms SC present the summary referred to in her interview to help learners remember when to calculate gradient and area, she also taught them how to do these calculations. She also used the magnitudes obtained from the calculations to sketch the corresponding graphs. This was also accompanied by a representation "walkingthe-graph" as a strategy to help learners conceptualise direction. Nevertheless, these adequate strategies were only applied in her discussion of graphs of motion at constant velocity, accelerated motion was not included. Hence we regarded her enacted competence as 'basic'.

\section{Case study 3 - Ms MH}

Table 8 summarises the levels at which we scored Ms MH's competences across the TSPCK components for both the reported and enacted PCK.

Table 8 A summary of Ms MH's competences in her reported and enacted PCK.

\begin{tabular}{|l|c|c|c|c|}
\hline TSPCK Component & Limited & Basic & Developing & Exemplary \\
\hline Learners' prior knowledge. & RE & & & \\
\hline Curricular saliency. & E & & R & \\
\hline What is difficult to teach? & & RE & & \\
\hline Representations including analogies. & E & R & & \\
\hline Conceptual teaching strategies. & E & $\mathbf{R}$ & & \\
\hline
\end{tabular}

Key: R - Reported PCK, E - Enacted PCK

Ms MH chose the following key ideas in her CoRe: (i) understanding definitions, (ii) motion at constant velocity, (iii) gradient, mathematically - change in y over change in $\mathrm{x}$, and scientifically - dependent over independent variable and (iv) the area underneath graphs.

\section{Learners' prior knowledge}

During the interview, Ms MH mentioned that learners do not understand the concept of 'deceleration': 
"If you talk about deceleration, learners do not understand that. Because they always think that 'Aowa [no] a car has an accelerator, so a car accelerates only'”,

However, an analysis of her CoRe revealed that she in fact had a misconception about this concept. She constructed a position-time (see Figure 3) graph but gave an incorrect description of the motion. She wrote "that an object can be constant, accelerate, stop and decelerate" whereas the last part of the graph actually shows an object returning to its starting point at a constant velocity. This suggests that she confused negative velocity with negative acceleration (McDermott et al. 1987). Consequently, we regarded her reported knowledge as 'limited', because her misunderstanding could be transferred to learners.

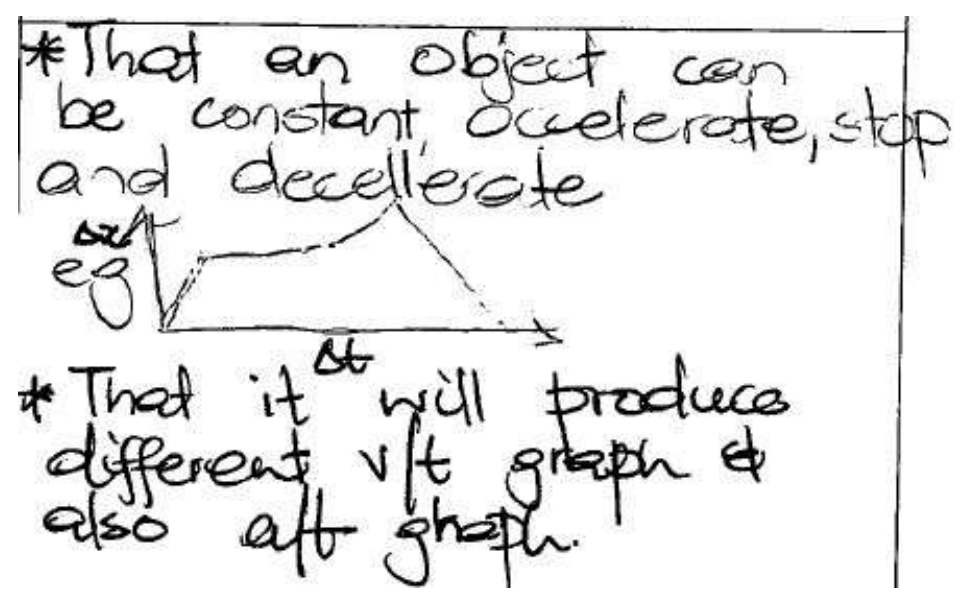

Fig. 3 Position-time graph drawn by Ms MH in the CoRe.

During the lesson, $\mathrm{Ms} \mathrm{MH}$ asked lower order questions to engage with learners' prior knowledge, suggesting a lower PCK base (Childs \& McNicholl 2007). For example, she asked learners to describe position, which one learner described correctly, saying "a point where you are standing". She rejected the answer and corrected it with "a point where you can find something", which does not give a better description. She also revealed that she has poor conceptual understanding, when asking: "which one between the two is a scalar, between position and displacement and which one is a vector? Then you will tell me, what is the difference between a scalar quantity and a vector quantity?" When learners answered incorrectly, saying a position is a scalar, she accepted the answer to be correct. Her lesson revealed that she actually transferred her lack of understanding of concepts to the learners. Hence we scored her enacted knowledge as 'limited'. 


\section{Curricular saliency}

In the CoRe Ms MH elaborated on the key ideas that she selected. She indicated how she sequenced concepts and how she explained the interrelatedness between the concepts. She defined gradient as "dependent over independent variable", and explained how she substituted motion variables into the gradient-formula to arrive at the definitions of velocity and acceleration. Similarly she mentioned the area under the velocity-time being displacement. Considering how she developed, sequenced and explained the interrelatedness between key ideas, we scored her reported knowledge as 'developing'.

During the lesson, Ms $\mathrm{MH}$ limited her actual teaching to graphs of motion at constant velocity. In contrast to her reported PCK, she did not develop and explain the interrelatedness between key ideas adequately. Although she mentioned gradient briefly, she did not show learners how it represents the definitions of velocity and acceleration. She merely said "in physical sciences, when we say calculate the velocity it's like we are saying find the gradient", not telling learners which graph she is referring to. Learners were then requested to calculate variables through the definitions of velocity and acceleration using tabulated data from a textbook without emphasis on the concept of gradient. The concept of area was not explained at all. She did not use the opportunities that arose to address it. As a result, we regarded her enacted knowledge as 'limited', two levels lower than her reported PCK suggested.

\section{What is difficult to teach?}

During the interview, Ms MH confidently mentioned that learners do not have a problem with plotting data in a graph, their only challenge is interpreting graphs. She added that this challenge is caused by the fact that they think all graphs represent motion at constant velocity. She also indicated in her CoRe that learners cannot identify shapes under a velocitytime graph representing accelerated motion to be able to calculate the area. She also added that learners' lack of understanding of mathematics and the English language are the major causes of the difficulties. As a result, we regarded her competence as 'basic'.

During the lesson, Ms MH did not confront all the concepts that she regarded as difficult. Although she identified difficulties related to graphs of accelerated motion in her reported PCK, her lesson covered graphs of motion at constant velocity, after which she instructed us that she had finished the topic. It is possible that she taught accelerated motion in our absence. We also observed that she did not teach the concept of area. Nevertheless, she 
revealed knowledge of learners' notion that on a position-time graph, motion in the negative direction should be indicated below the horizontal axis. She addressed this difficulty by constructing and interpreting a decreasing position-time graph (with positive position values) showing an object moving in the negative direction. She correctly mentioned that the graph doesn't necessarily have to be constructed below the horizontal axis where position is negative. Considering that she helped learners interpret direction in a position-time graph, we regarded her enacted knowledge of difficult concepts as 'basic'.

\section{Representations including analogies}

When prompted about useful representations in this topic Ms MH said "in most cases I use a ticker timer, that's the only thing... if they [learners] are able to calculate velocity and acceleration from the ticker timer, they would be able to draw a velocity-time graph, acceleration-time graph and even displacement-time graph". However, she did not adequately indicate how the data from this experiment is employed to support the conceptual development of displacement, velocity and acceleration. Following her inability to clearly support her use of ticker timer experiments and to identify other useful representations, we regarded her reported competence as 'basic'. During the lesson, Ms MH did not attempt to use ticker timer experiment that she had indicated in her reported PCK or any other representation in her lesson, hence we regarded her enacted knowledge as 'limited'.

\section{Conceptual teaching strategies}

Ms MH advocated the idea of teaching this topic by firstly exploring learners' understanding of prior knowledge. However, her strategy to confront learners' misunderstanding of the concept of 'deceleration' was inadequate because it revealed that she in fact had a misconception regarding the concept. She also indicated a strategy that she used to develop new knowledge from learners' prior knowledge of mathematics, gradient and area She said "I normally ask them "find the gradient", then if they labelled the graph correctly, for example if the y-intercept is displacement and the $\mathrm{x}$-intercept is time then that will give them velocity." The part that says "if they labelled their graph correctly" suggests that learners were more involved in her lessons. She also regarded a ticker timer experiment as a strategy that helps learners visualise graphs. Consequently, we regarded her reported knowledge as 'basic'.

During her lesson, she engaged with learners' prior knowledge by asking lower order questions, for example, units of measurements of motion variables. Some of her questions 
and responses to learners' answers had the potential to induce misconceptions as we have shown under the first TSPCK component. Nevertheless, the involvement of learners was evident. She requested them to calculate motion variables using definitions of velocity and acceleration, and to sketch the corresponding graphs based on their calculations. Her lesson presentation fell short because she did not emphasise the fact that the definitions of velocity and acceleration represent gradients of position-time and velocity-time graphs respectively. Her teaching approach promoted familiarity with algebra rather than the conceptual physics behind the calculation (Rollnick et al. 2008; Woolnough 2000). She also did not use any representations, and at times she incorporated incorrect concepts which inevitably results in poor PCK (Smith \& Banilower 2015). As a result, we regarded her enacted competence as 'limited'.

\section{Case study 4 - Mr KZ}

Table 9 summarises the levels at which we scored Mr KZ's competences across the TSPCK components for both the reported and enacted PCK.

Table 9 A summary of Mr KZ's competences in his reported and enacted PCK.

\begin{tabular}{|l|c|c|c|c|}
\hline TSPCK Component & Limited & Basic & Developing & Exemplary \\
\hline Learners' prior knowledge. & & & $\mathbf{R E}$ & \\
\hline Curricular saliency. & & $\mathbf{E}$ & $\mathbf{R}$ & \\
\hline What is difficult to teach? & & & $\mathbf{R E}$ & \\
\hline Representations including analogies. & & $\mathbf{R}$ & $\mathbf{E}$ & \\
\hline Conceptual teaching strategies. & & $\mathbf{E}$ & $\mathbf{R}$ & \\
\hline
\end{tabular}

Key: R - Reported PCK, E - Enacted PCK

Mr KZ chose the following key ideas in his CoRe: (i) position-time, (ii) velocity-time, (iii) acceleration-time graphs, (iv) gradient of a position-time and velocity-time graph, and (v) area under a velocity-time graph. His CoRe was completed up to the fourth prompt. As such we had scant information about some of the components as revealed in the written CoRe of this teacher.

\section{Learners' prior knowledge}

Mr KZ showed awareness of learners' misconceptions, pointing out that learners believe that an object moving in a straight line (one dimension) can change direction without having to stop. He also mentioned that this misunderstanding is perpetuated by everyday experiences, not limited to one dimension, where learners see objects changing direction without stopping. 
He also mentioned that learners confuse the direction of velocity with that of acceleration (McDermott et al. 1987), that is, they don't understand what it means to have acceleration and velocity in the same or opposite directions. Based on the misconceptions that he indicated, we scored his reported PCK in this component as 'developing'. During his lesson, $\mathrm{Mr} \mathrm{KZ}$ used questions to uncover the misconception about objects changing direction while moving in a straight line. He addressed the misconception by walking in a curved path and a straight line to show learners that in two dimensions direction can be changed without stopping, but not in one dimension. However, the misconception about the direction of velocity and acceleration was not assessed in the lesson. Nevertheless, we regarded his enacted PCK as 'developing' considering that he adequately addressed one of the identified misconceptions.

\section{Curricular saliency}

In the CoRe, Mr KZ elaborated on all the key ideas that he initially chose. He mentioned the importance of developing concepts using learners' prior mathematical knowledge of gradient and area. He indicated an acceptable teaching sequence of graphs of motion and explained how he uses gradient and area to explain their interrelatedness. During the interview, he said "velocity is the rate of change of position, so when we look at our graph, y [vertical axis] represents position and $\mathrm{x}$ [horizontal axis] represents time, the gradient that I will have for a position-time graph is gonna [going to] give me velocity". Hence we regarded his reported PCK as 'developing'. During the lesson, Mr KZ spent most of the time explaining graphs of motion at constant velocity but did not discuss graphs of accelerated motion. In fact he hardly ever mentioned acceleration during the lesson. Hence he only explained the gradient of a position-time graph but not the gradient of a velocity-time graph. Furthermore, the concept of area under graphs was not discussed altogether. Hence the sequencing and the interrelatedness between concepts were limited to the concepts taught in our presence. Hence we scored Mr KZ's enacted PCK as 'basic'.

\section{What is difficult to teach?}

During the interview, Mr KZ expanded on the misconception about changing the direction of motion in a straight line and how it hinders learners' understanding of graphs of motion. $\mathrm{He}$ mentioned that learners do not understand the graphical representation of changing direction, especially in a velocity-time graph. He further mentioned that learners find it difficult to interpret graphs of motion because they focus only on the shapes of the graphs, without 
checking the variables. Hence they believe that an increasing position-time graph with a constant gradient indicates that an object is speeding up, related to the slope-height misconception (Nemirovsky \& Rubin 1992). He also argued that referring to the area "under" a velocity-time graph as presented in learning material confuses learners, and advocated that it should be the area "between the graph and the horizontal axis". Considering the concepts that he regarded as difficult and how learning materials have the potential to confuse learners, we rated his reported PCK as 'developing'.

During the lesson, he thoroughly addressed the concepts that he regarded as difficult. He constructed an increasing position-time graph with a constant gradient and asked learners to comment on the velocity of the motion, upon which they said the velocity is increasing. He addressed this misunderstanding by alerting learners that since the gradient of the graph, which represents velocity, is constant, the velocity should also be constant. He also assisted them to understand the graphical representation of a change of direction in a velocity-time graph, demonstrating by walking in a straight line, that he had to stop before changing direction. Judging by the way he adequately addressed some of the difficult concepts, we scored his enacted knowledge of this component as 'developing'.

\section{Representations including analogies}

During the interview, Mr KZ suggested that "walking-the-graph" is a useful representation to help learners visualise motion. However, he did not specifically indicate the concepts and ideas that are developed through this representation. This doesn't imply that he did not know this, as respondents were not instructed to write down everything they knew, an indication of the limitation of the CoRe tool. On the other hand we also cannot assume that he knew all the concepts that can be supported by this representation. Hence we regarded his reported knowledge about representations as 'basic'. In contrast, during the lesson it became clear that he had this knowledge as he specifically referred to position and velocity while using the representation. In particular, he used this representation to support the interpretation of position- and velocity-time graphs, and to address a misconception when he demonstrated by walking that an object moving in a straight line has to stop before it changes direction. Hence we regarded his enacted knowledge of representations as 'developing'. This example illustrates the gap between reported and enacted PCK. 


\section{Conceptual teaching strategies}

Mr KZ did not just reveal awareness of learners' difficulties, he also indicated strategies that he used to uncover and address those difficulties to develop and support learners' conceptual understanding. During the interview, he constructed two position-time graphs (Figure 4) on the same set of axes and mentioned that he asks learners to comment on the velocities. He also indicated the common response that he gets from learners, which is "the object that starts from zero is speeding up while the one that starts from 20 metres is slowing down".

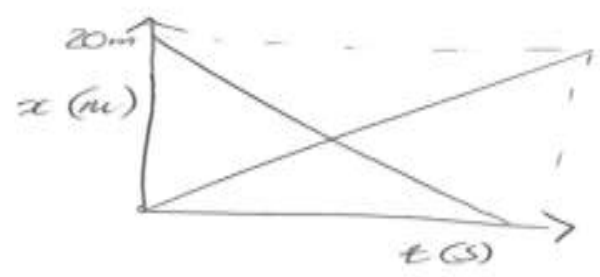

Fig. 4 Position-time graph drawn by Mr KZ during the interview.

He also indicated that he explains kinematics concepts using learners' prior knowledge of mathematics. He described how he explains the idea that the area under the velocity-time graph, which is length (velocity) multiplied by width (time), represents displacement. $\mathrm{Mr}$ KZ's knowledge of representations as a teaching strategy was restricted by the fact that he did not specify which concepts are aided by "walking-the-graph". Nevertheless, we scored his reported knowledge of teaching strategies as 'developing'.

During the lesson, Mr KZ facilitated discussions that revealed learners' misconceptions and difficulties, which he addressed using representations where necessary. However, in one episode he prevented learners from thinking that time is a vector by asking a question and responding to it himself:

"Why don't we have the negative $y$ and the negative $x$ on this graph? Because time cannot be negative, remember time is a scalar quantity therefore you can't say negative time represents the opposite direction"

The biggest downfall to his teaching strategies is the fact that he wanted to cover the whole topic in two periods. The majority of concepts related to accelerated motion partially discussed, hence learners were not enabled to conceptually understand the topic as a whole. It is possible that he may have taught the concepts in our absence and that time limitations could have restricted his teaching during our visits. However, he adequately explained the 
concepts that he taught in our presence. In his discussion of the interrelatedness between a position-time and a velocity-time graph, he ensured that learners understood how the gradient of a position-time graph represents velocity. He then calculated gradients at different point on the graph, with the aid of his learners, and used the magnitudes to construct the corresponding velocity-time graph. Based on his teaching, we have scored his knowledge of teaching strategies as 'basic'.

\section{Discussions of the results}

The individual cases of the teachers showed that their scores in the enacted PCK components were predominantly lower, or at best similar to those in the reported PCK. A similar result was reported by Alonzo and Kim (2016), who found that teachers' dynamic PCK relied heavily on their declarative PCK. The teachers in the current study managed to put their knowledge about teaching this topic into practice in some of the components. In Ms SC's case this was evident in four components whereas for the other teachers it was evident in only two components each. The same level of reported and enacted PCK does not necessarily mean the teacher enacted exactly what his/her reported PCK had suggested, but rather that the level of agreement was not significantly different. For example, Ms SC was scored 'basic' in her knowledge of representations in the reported and the enacted PCK although she incorporated a different representation during teaching "walking-the-graph" from what her reported PCK suggested (ticker timer experiments).

All the teachers had at least one component in which their enacted PCK was one level lower than the reported PCK. Similarly, Alonzo and Kim (2016) also reported that in some cases, teachers with a high declarative PCK knowledge base enacted low dynamic PCK bases. In the current study, the teachers had pedagogically rich knowledge for engaging with the specific components in their reported PCK. Unfortunately they failed to translate the knowledge into practice. For Ms MH, this translation of her reported PCK was restricted by her lack of content knowledge. Her case in fact supports findings reported in literature that a lack of content knowledge usually leads to poor PCK (Rollnick et al. 2008) and that incorporating incorrect content into planning and teaching inevitably amounts to inadequate PCK (Smith \& Banilower 2015). She was the only teacher whose enacted competence was two levels lower than suggested by her reported PCK, regarding her knowledge of curricular saliency. It is not clear how or why the lack of content knowledge was more evident in her enacted PCK, contrary to findings reported in literature that it affects different manifestations 
of PCK (Alonzo \& Kim 2016; Mdolo \& Mundalamo 2015). This may mean that poor conceptual understanding can be obscured in reporting PCK, but not in the interactive environment of the classroom where deep understanding is required to integrate knowledge in the enactment of PCK. The translation of the teachers' reported PCK was also affected by their reluctance to adequately teach graphs of accelerated motion. It is possible that the need to finish the lesson made the teachers to rush through the concepts.

The intriguing outcome of this study was the few cases whereby teachers enacted a higher PCK competence than was suggested by their reported PCK. This was observed for Ms VM and $\mathrm{Mr} \mathrm{KZ}$ in curricular saliency and representations respectively. The teachers inadequately reported their knowledge of teaching with regard to those components. Ms VM had omitted the importance of the concept of gradient and area in the CoRe and the interview, whereas she explained the interrelatedness of the graphs through the concept of gradient during teaching. Mr. KZ on the other hand used representations to address learners' misconceptions during teaching, but this knowledge was not evident in his reported PCK. This emphasises the tacit nature of PCK (Kagan 1990) because the teachers found it difficult to formulate their PCK in writing, but when they were faced with challenges of the classroom, they were able to utilise their dynamic forms of PCK (Alonzo \& Kim 2016).

\section{Concluding remarks}

The separate analysis of teachers' reported and enacted PCK revealed that they seldom portrayed the same level of competence in all five TSPCK components. This indicates the importance of exploring a multitude of components defining PCK when studying this construct as competence in one component is not a reflection of the other components. The results have also shown that level of agreement between the reported and the enacted PCK varied. One manifestation of PCK did not necessarily reflect the other, thus it is important to explore both of them not only because of the variations, but also because PCK encompasses both understanding and enactment (Park \& Oliver 2008). Exploring both forms of PCK is also important in PCK development because the acquisition and enactment of learnt PCK are two intertwined events (Park \& Oliver 2008). These variations support the claim by Park \& Oliver (2008) that PCK is not a fixed construct, and that its application depends on context as well as interaction with learners.

The first limitation of this study was that there was no way to ensure that participants thought about and revealed everything they knew when they completed the CoRe tool. In fact most of 
them left some prompts unanswered. Secondly, some of the teachers rushed through their explanations of some of the concepts during teaching, especially graphs of accelerated motion, in order to finish as planned. Although we dealt with the issue of bias, the interpretation of the data may have been influenced by our own perceptions of the way this topic should be taught. Based on the results, we recommend further studies to explore the significance of the gap between reported and enacted PCK. Finally, the implication for teacher training is that student teachers should not only learn content knowledge and theoretical PCK, but they should also be trained to enact this PCK in the interactive classroom situation.

\section{References}

Abell, S. K. (2008). Twenty years later: does pedagogical content knowledge remain a useful idea? Internation Journal of Science Education, 30(10), 1405-1416.

Alonzo, A. C., \& Kim, J. (2016). Declarative and dynamic pedagogical content knowledge as elicited through two video-based interview methods. Journal of Research in Science Teaching, 53(8), 1259-1286.

Ayadin, S., \& Boz, Y. (2012). Review of studies related to pedagogical content knowledge in the context of science teacher education: Turkish case. Educational Sciences: Theory \& Practice, 12(1), 497-505.

Barclay, W., L. (1985). Graphing Misconceptions and Possible Remedies Using MicrocomputerBased Labs. Paper presented at the 7th National Educational Computing Conference, University of San Diego, San Diego, CA.

Baxter, J. A, \& Lederman, N., G. (1999). Assessment and measurement of pedagogical content knowledge. In J. Gess-Newsome \& N. Lederman, G, (Eds.), Examining pedagogical content knowledge (pp. 147-161). Netherlands: Kluwer Academic Publishers.

Bertram, A., \& Loughran, J. (2012). Science teachers' views on CoRes and PaP-eRs as a framework for articulating and developing pedagogical content knowledge. Research in Science Education, 42(6), 1027-1047.

Chantaranima, T., \& Yuenyong, C. (2014). The Pedagogical Content Knowledge Exploration from the Thai Expert Physics Teacher's Class. Procedia-Social and Behavioral Sciences, 116, 389393.

Chapoo, S., Thathong, K., \& Halim, L. (2014). Understanding Biology Teacher's Pedagogical Content Knowledge for Teaching "The Nature of Organism". Procedia-Social and Behavioral Sciences, 116, 464-471.

Childs, A., \& McNicholl, J. (2007). Investigating the relationship between subject content knowledge and pedagogical practice through the analysis of classroom discourse. International Journal of Science Education, 29(13), 1629-1653.

Chordnork, B., \& Yuenyong, C. (2014). Constructing CoRe as a Methodological for Capturing Pedagogical Content Knowledge: A Case Study of Thailand Teachers Teaching Global Warming. Procedia-Social and Behavioral Sciences, 116, 421-425.

Clement, J. (1985). Misconceptions in graphing. Paper presented at the Proceedings of the Ninth International Conference for the Psychology of Mathematics Education. 
Cochran, K. F, King, R. A, DeRuiter, J. A. (1991). Pedagogical Content Knowledge: A Tentative Model for Teacher Preparation. East Lansing, MI: National Center for Research on Teacher Learning. (ERIC Document Reproduction Service No. ED340683)

Department of Basic Education. (2011). Curriculum and Assessment Policy Statement. Grades $10-12$ physical sciences. Pretoria: Government Printer.

Eames, C. W., Williams, P. J., Hume, A. C., \& Lockley, J. (2011). CoRe: A way to build pedagogical content knowledge for beginning teachers [electronic version]. Teaching and Learning Research Initiative. Retrieved from: http://researchcommons.waikato.ac.nz/handle/10289/7399.

Frauenknecht, R. \& Jordaan, F. (2005). Students' understanding and use of gradient in kinematic graphs. Journal of Science Education 6(1), 31-36.

Grossman, P., L. (1990). The making of a teacher: Teacher knowledge and teacher education. New York: Teachers college press.

Halloun, I. A., \& Hestenes, D. (1985). Common sense concepts about motion. American journal of physics, 53(11), 1056-1065.

Hancock, B. (2002). Trent Focus for Research and Development in Primary Health Care: An Introduction to Qualitative Research. Book. University of Nottingham. Nottingham.

Hashweh, M. Z. (2005). Teacher pedagogical constructions: a reconfiguration of pedagogical content knowledge. Teachers and Teaching: Theory and practice, 11(3), 273-292.

Heller, J. I., Daehler, K. R., Shinohara, M., \& Kaskowitz, S. R. (2004). Fostering pedagogical content knowledge about electric circuits through case-based professional development. Paper presented at the annual meeting of the National Association for Research in Science Teaching (NARST), Vancouver, Canada.

Jüttner, M., \& Neuhaus, B. J. (2012). Development of items for a pedagogical content knowledge test based on empirical analysis of pupils' errors. International Journal of Science Education, 34(7), 1125-1143.

Kagan, D. M. (1990). Ways of evaluating teacher cognition: Inferences concerning the Goldilocks principle. Review of educational research, 60(3), 419-469.

Lapp, D. A., \& Cyrus, V. F. (2000). Using data-collection devices to enhance students' understanding. Mathematics Teacher, 93(6), 504-510.

Lemmer, M. (2013). Nature, cause and effect of students' intuitive conceptions regarding changes in velocity. International Journal of Science Education, 35(2), 239-261.

Loewenberg Ball, D. L., Thames, M. H., \& Phelps, G. (2008). Content knowledge for teaching: What makes it special? Journal of teacher education, 59(5), 389-407.

Loughran, J., Mulhall, P., \& Berry, A. (2004). In search of pedagogical content knowledge in science: Developing ways of articulating and documenting professional practice. Journal of research in science teaching, 41(4), 370-391.

Magnusson, S., Krajcik, J., \& Borko, H. (1999). Nature, sources, and development of pedagogical content knowledge for science teaching Examining pedagogical content knowledge (pp. 95132): Springer.

Maree, J. G. (2010). First steps in research. Pretoria: Van Schaik Publishers.

Mavhunga, E., \& Rollnick, M. (2013). Improving PCK of chemical equilibrium in pre-service teachers. African Journal of Research in Mathematics, Science and Technology Education, 17(1-2), 113-125.

Mazibe, E. N. (2017). Teaching graphs of motion: translating pedagogical content knowledge into practice.Master's dissertation, University of Pretoria, Pretoria. Retrieved from http://hdl.handle.net/2263/62885 
McDermott, L. C., Rosenquist, M. L., \& Van Zee, E. H. (1987). Student difficulties in connecting graphs and physics: Examples from kinematics. American journal of physics, 55(6), 503-513.

Mdolo, M. M., \& Mundalamo, F. J. (2015). Teacher knowledge shaping the teaching of genetics: a case study of two underqualified teachers in Malawi. African Journal of Research in Mathematics, Science and Technology Education, 19(1), 1-11.

Mishra, P., \& Koehler, M. (2006). Technological pedagogical content knowledge: A framework for teacher knowledge. The Teachers College Record, 108(6), 1017-1054.

Nemirovsky, R., \& Rubin, A. (1992). Students' Tendency To Assume Resemblances between a Function and Its Derivative. TERC working paper, 2 - 92, Cambridge, MA: TERC Communications.

Padilla, K., Ponce-de-León, A. M., Rembado, F. M., \& Garritz, A. (2008). Undergraduate professors' pedagogical content knowledge: The case of 'amount of substance'. International Journal of Science Education, 30(10), 1389-1404.

Park, S., \& Oliver, J. S. (2008). Revisiting the conceptualisation of pedagogical content knowledge (PCK): PCK as a conceptual tool to understand teachers as professionals. Research in Science Education, 38(3), 261-284.

Park, S., Jang, J. Y., Chen, Y. C., \& Jung, J. (2011). Is pedagogical content knowledge (PCK) necessary for reformed science teaching?: Evidence from an empirical study. Research in Science Education, 41(2), 245-260.

Rollnick, M., Bennett, J., Rhemtula, M., Dharsey, N., \& Ndlovu, T. (2008). The place of subject matter knowledge in pedagogical content knowledge: A case study of South African teachers teaching the amount of substance and chemical equilibrium. International Journal of Science Education, 30(10), 1365-1387.

Shulman, L. (1987). Knowledge and teaching: Foundations of the new reform. Harvard educational review, 57(1), 1-23.

Shulman, L. S. (1986). Those who understand: Knowledge growth in teaching. Educational researcher, 4-14.

Smith, S., \& Banilower, E. (2015). Assessing PCK: A new application of the uncertainty principle. In A. Berry, P. Friedrichsen, \& J. Loughran (Eds.), Re-examining pedagogical content knowledge inscience education (pp. 89-103). London: Routledge Press.

Van Der Valk, T., \& Broekman, H. (1999). The lesson preparation method: A way of investigating pre-service teachers' pedagogical content knowledge. European Journal of Teacher Education, 22(1), 11-22.

Van Driel, J. H., Verloop, N., \& de Vos, W. (1998). Developing science teachers' pedagogical content knowledge. Journal of research in science teaching, 35(6), 673-695.

Veal, W. R., \& MaKinster, J. G. (1999). Pedagogical Content Knowledge taxonomies. Electronic Journal of Science Education, 3(4).

Veal, W. R., Tippins, D. J., \& Bell, J. (1999). The Evolution of Pedagogical Content Knowledge in Prospective Secondary Physics Teachers. (No. ED443719). Indiana, IN, USA: Indiana University.

Woolnough, J. (2000). How do students learn to apply their mathematical knowledge to interpret graphs in physics? Research in Science Education 30(3), 259-267. 